\title{
ASSESSMENT OF THE SOCIO-DEMOGRAPHIC AND ECONOMIC RISK FACTORS OF CHILDHOOD DISEASES AND MORTALITY IN YAMALTU DEBA LOCAL GOVERNMENT AREA, GOMBE STATE, NIGERIA
}

\author{
Rhoda Mundi ${ }^{1}$, Dakyes Samuel Panse ${ }^{1}$, Ishaya Sunday ${ }^{1}$, \\ Nwankwo Beatrice Biyaya ${ }^{1}$ and Stephen Yohanna ${ }^{2}$ \\ ${ }^{1}$ University of Abuja, Nigeria \\ ${ }^{2}$ Bingham University, Karu, Nigeria, \\ Corresponding author: samuelpanse@gmail.com
}

\begin{abstract}
Cite this article:
Mundi R., Dakyes S.P., Ishaya S., Nwankwo B.B. Yohana S. (2022), Assessment of the Socio-Demographic and Economic Risk Factors of Childhood Diseases and Mortality in Yamaltu Deba Local Government Area, Gombe State, Nigeria. African Journal of Health, Nursing and Midwifery 5(1), 37-54. DOI: 10.52589/AJHNMHFE9JUAD
\end{abstract}

\section{Manuscript History \\ Received: 10 Jan 2022 \\ Accepted: 31 Jan 2022 \\ Published: 3 March 2022}

Copyright $\odot 2022$ The Author(s). This is an Open Access article distributed under the terms of Creative Commons AttributionNonCommercial-NoDerivatives 4.0 International (CC BY-NC-ND 4.0 ), which permits anyone to share, use, reproduce and redistribute in any medium, provided the original author and source are credited.
ABSTRACT: The study Assessed major childhood diseases and child mortality in Yamaltu/Deba Local Government Area of Gombe State. It also analyzed the complex socio-economic and cultural factors that influence the distribution of diseases and mortality in the study area. Data on childhood diseases and mortality were collected from hospital visits of children aged 0-5 years at Deba General Hospital during the 10-year period from 2007-2016. Five percent of the records were sampled. Data on the demographic, socio-economic and cultural factors of respondents were collected with the aid of questionnaires, Focus Group Discussions (FGDs) and In-Depth Interviews (IDIs) to explain perceptions and attitudes regarding the major diseases and child mortality in the study area. The sample size was determined from one-third of the households in the study area. One hundred respondents were selected from 21 settlements in the 11 wards of the study area, using a systematic sampling technique. Descriptive and Inferential Statistics (regression analysis, Pearson's correlation and ANOVA) were used in analyzing the results. The results show malaria, diarrhoea and other fevers as the major childhood diseases; with variation in childhood mortality as influenced by the demographic, socio-economic, and cultural characteristics of parents. The regression analysis with an $R$-value of 0.860 indicates a very high degree of correlation among the variables. It indicates that $70 \%$ of the diseases caused can be explained or accounted for by income, religion, occupation and education. The regression analyses Coefficients indicate that Religion and Education significantly predict "Disease". The result further indicates that "Religion" which yielded a Beta ( $\beta$ ) value of .862, $t$-value of 3.102, and a p-value of .002, and "Education" which yielded a Beta $(\beta)$ value of $.760, t$-value of 2.058 , and a $p$-value of .040 were significant. Similarly, regression analysis for mortality with an $R$-value of 0.536 indicates a high degree of correlation among the variables in the model. This shows that $41.8 \%$ of the mortality causes can be explained or accounted for by income, religion, occupation and education. The result of the analysis also shows that healthcare facilities in the area are not efficiently located. The study recommended that Programmes and policies aimed at addressing the health needs and economic empowerment of the population should be put in place in the study area.

KEYWORDS: Childhood Diseases, Mortality, Mapping, Health Care Facilities. 


\section{INTRODUCTION}

For most of human history, infectious diseases have been the major cause of death in children and adults killing them before they had a chance to die of something else. Available data particularly in Nigeria shows that children die from major diseases such as malaria, diarrhoea, respiratory diseases, particularly pneumonia, and AIDS, among others ( http://www.nigerian bullentin.com. Posted Jul 2, 2015). According to the World Bank, some 11 million children die annually globally with sub-Saharan Africa being most affected and accounting for more than one-third of the deaths even when the region accounts for only one-fifth of the world's child population (WHO, 2005). It is estimated that worldwide 16,087 infants die every day, with 10 deaths occurring every minute. However, there is a sharp difference between the developed and less developed countries with 197 infant deaths per day and 0.1 per minute in the developed world, compared to 14,890 deaths per day and 10 per minute in the less developed countries (http://www.prb.org/pdf14/2014-worldpopulationdata-sheet_eng.pdf).

Data from the Nigerian National Demographic and Health Survey (NDHS) 2013 indicates that under-five mortality rates are higher in Northern than Southern Nigeria. The data further revealed that the North West has the highest rate of 185 deaths per 1000 live births followed by the North East and North Central with 160 deaths and 100 deaths per 1000 live births respectively. The South East, South-South and South-West recorded 131, 91 and 90 deaths each per 1000 live births. The report also shows that mortality rates are influenced by socioeconomic, environmental and cultural factors.

Most studies in Nigeria tend to look at the prevalence of certain specific diseases and/or the determinants of such diseases. Gayawan et al (2014), relied on data from the 2010 Malaria Indicator Survey (NMIS) and established that there was a distinct North-South divide in the concentration of under-five children with malaria and a higher risk of anaemia. Other studies on the prevalence of malaria from different parts of Nigeria include those of Nwaorgu and Rajaka (2011) in Awka LGA, Anambra State; Ezeigbo et al (2014) in Aba both in SouthEastern Nigeria; Jombo et al (2010) in Makurdi, North Central Nigeria; Umaru and Uyaiabasi(2015) in Makarfi, North-Western Nigeria and Kunihya et al (2016) in Yola, NorthEastern Nigeria. Feyisetan et al (1997) identified poor health service delivery and ignorance associated with cultural beliefs as contributory to childhood mortality due to malaria and suggested that social and cultural determinants of behaviour may account for the gap between awareness of modern health measures and health-seeking behaviour.

A proper understanding of the determinants of morbidity and mortality in a given community is crucial to the success of any policy or health care intervention that may be initiated. At present, much of the information is derived from data from health facilities. Unfortunately, such information represents only a small proportion of all illnesses, because many cases do not seek medical attention in such facilities.

This paper identifies the major under-five diseases, ascertain the socioeconomic and cultural factors that contribute to the prevalence of these diseases and map the distribution of healthcare facilities in Yamaltu/Deba Local Government Area of Gombe State, North-East Nigeria. 


\section{MATERIALS AND METHODOLOGY}

\section{Study Area}

The study was conducted in Yamaltu/Deba Local Government Area of Gombe State, Nigeria. Gombe State is located between latitudes $10^{\circ} 0^{\prime}$ and $10^{\circ} 20^{\prime} \mathrm{N}$ and on longitudes $11^{\circ} 1^{\prime}$ and $11^{\circ} 19^{\prime} \mathrm{E}$. It has a total Land Area of $18,768 \mathrm{Km}^{2}$ and a total population of 2,353,000 based on the 2006 census figure. It has 11 Local Government Areas including Yamaltu/Deba, with Headquarters at Deba. Yamaltu/Deba Local Government Area is made up of 11 wards. (See Figure 1). Its ethnic composition includes mainly the Fulani/Fulfulde, Hausa, Tangale, Tera, and Waja among others.

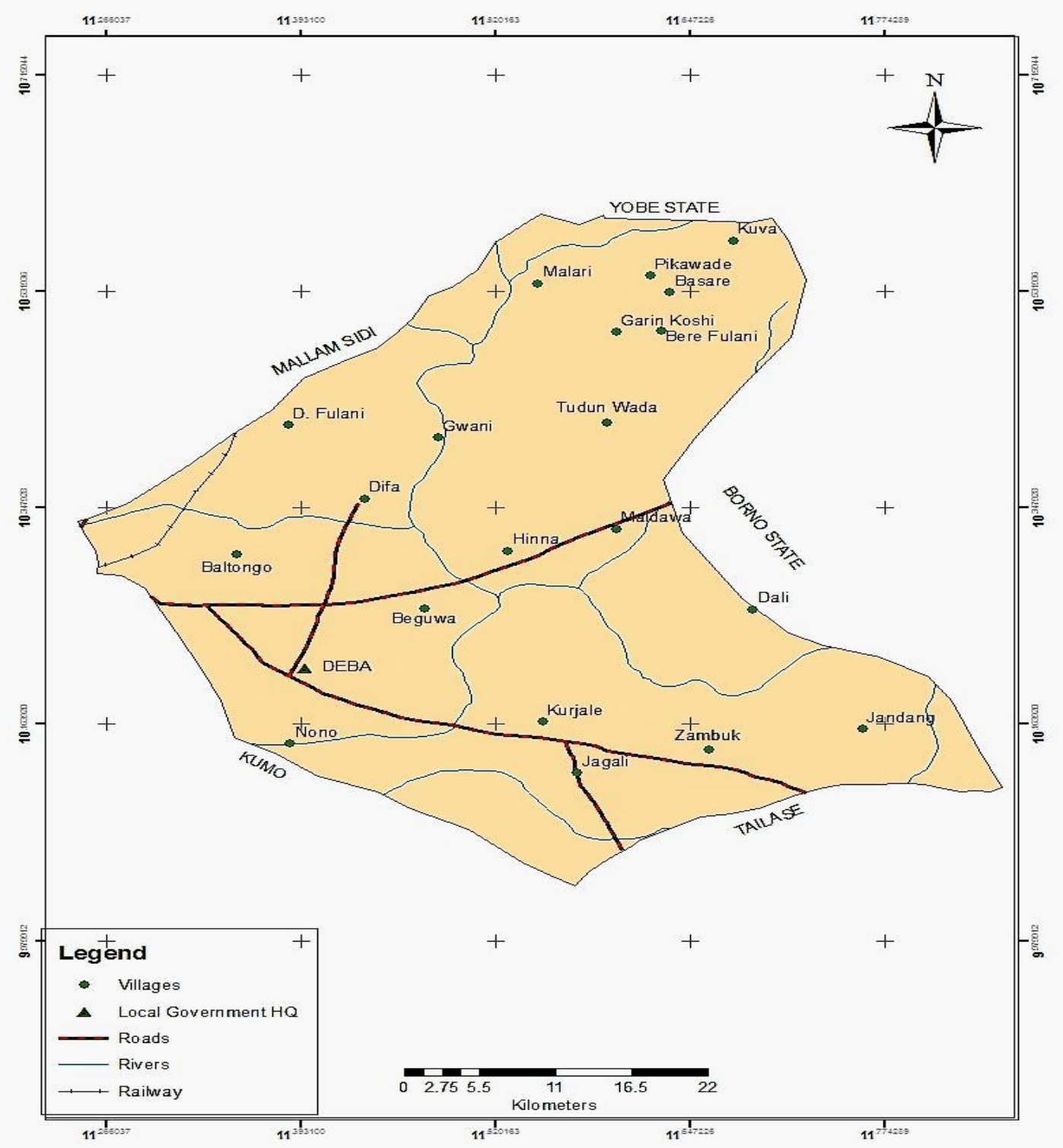

Fig 1: Yamaltu/Deba Local Government Area. Gombe State 


\section{Study Design}

Data on childhood morbidity and mortality were collected from records of children aged 0-5 years at Deba General Hospital, during the 10-year period from 2007-2016. Ten percent of the records were sampled. The data retrieved included the disease type, age, sex, and domicile of the child. The demographic, socio-economic and cultural characteristics of respondents were collected with the aid of a questionnaire. Focus Group Discussions (FGDs) involving women and men groups were also conducted as well as In-Depth Interviews (IDIs) with opinion leaders within the communities to explore the perceptions and attitudes of people regarding the major diseases and child mortality in the area. The major instruments used for the data collection include questionnaires and a tape recorder/Notebook for FGDs and IDIs among others.

\section{Sample Size}

The sample size was determined from one-third of the households in the study area. One hundred respondents were selected from 21 settlements in the 11 wards of the study area, using a systematic sampling technique.

\section{Data Analysis}

The SPSS statistical software (version 23.0) was used to analyze the data. Descriptive statistics such as frequency tables, percentages and charts/graphs were used in the data analysis. Inferential statistics especially regression analysis, Pearson's correlation and ANOVA were used to test for relationships between certain variables.

\section{Ethical Consideration.}

A letter of ethical clearance to conduct the study was obtained from the Gombe State Ministry of Health. Permission to access the medical records of the children was obtained from the Medical Director and the Head of Medical Records Unit of Deba General Hospital. For every community entered, the consent of the community leader, as well as the respondent, was obtained before the commencement of the exercise in that community. Participation in the FGDs/IDIs was voluntary.

\section{RESULTS AND DISCUSSION}

\section{Socio-Demographic Characteristics of the Children}

Table 1 shows that $1,748(51.9 \%)$ of the 3,368 children who visited the hospital during the study period were females while $1,620(48.1 \%)$ were males, giving a female: male ratio of 1:0.92. Fifty percent of the children were between ages $1-5$ years while about $15.3 \%$ were less than one month of age and $34.7 \%$ were between 1-12 months of age. The majority $(70.1 \%)$ of the children were from rural areas and mostly from polygamous families. The Table also reveals that $11.5 \%$ of the children were from a family size of fewer than 3 persons. About $54.5 \%$ of them were from families with a large family size of 5 and above. The majority $(53.3 \%)$ of the children were in birth order 4-6 while $22.5 \%$ were in the birth order of 7 and above. 
African Journal of Health, Nursing and Midwifery

ISSN: 2689-9418

Volume 5, Issue 1, 2022 (pp. 37-54)

www.abjournals.org

Table 1: Sociodemographic characteristics of Children in the study Area

\begin{tabular}{|c|c|c|}
\hline Variable & Number of Children & $\begin{array}{l}\text { Perce } \\
\mathrm{t}\end{array}$ \\
\hline \multicolumn{3}{|l|}{ Sex } \\
\hline Male & 1620 & 48.1 \\
\hline Female & 1748 & 51.9 \\
\hline \multicolumn{3}{|l|}{ Age } \\
\hline Less than 1 month & 513 & 15.3 \\
\hline $1-12$ months & 1170 & 34.7 \\
\hline $13-60$ months & 1685 & 50.0 \\
\hline \multicolumn{3}{|l|}{ Residence } \\
\hline Urban & 1007 & 29.9 \\
\hline Rural & 2361 & 70.1 \\
\hline \multicolumn{3}{|l|}{ Family Type } \\
\hline Monogamous & 490 & 14.5 \\
\hline Polygamous & 2788 & 82.8 \\
\hline Single Parent & 90 & 2.7 \\
\hline \multicolumn{3}{|l|}{ Family size } \\
\hline$<3$ & 815 & 11.5 \\
\hline $3-4$ & 1794 & 33.9 \\
\hline $5-6$ & 900 & 26.7 \\
\hline $7-8$ & 511 & 15.2 \\
\hline$>8$ & 426 & 12.6 \\
\hline \multicolumn{3}{|l|}{ Birth Order } \\
\hline $1-3$ & 815 & 24.2 \\
\hline $4-6$ & 1794 & 53.3 \\
\hline $7-9$ & 490 & 14.5 \\
\hline 10 and above & 269 & 8.0 \\
\hline
\end{tabular}

Source: Hospital Record and data analysis 2019

Socio-Demographic and Economic Characteristics of the Parents.

Information on the socio-demographic and economic characteristics of the respondents was analyzed and presented in table 2 . 
African Journal of Health, Nursing and Midwifery

ISSN: 2689-9418

Volume 5, Issue 1, 2022 (pp. 37-54)

www.abjournals.org

Table 2: Socio-demographic and economic Characteristics of Parents of the children

\begin{tabular}{|c|c|c|c|c|c|c|}
\hline \multirow[t]{2}{*}{ Variable } & \multicolumn{2}{|l|}{ Mother } & \multicolumn{2}{|l|}{ Father } & \multicolumn{2}{|l|}{ Total } \\
\hline & Respondents & Percent & Respondents & Percent & Respondents & Percent \\
\hline \multicolumn{7}{|l|}{ Age (years) } \\
\hline $15-19$ & 357 & 10.6 & 96 & 2.9 & 453 & 6.7 \\
\hline $20-24$ & 1402 & 41.6 & 373 & 11.1 & 1775 & 26.3 \\
\hline $25-29$ & 1192 & 35.4 & 801 & 23.8 & 1993 & 29.5 \\
\hline $30-34$ & 370 & 11.0 & 1339 & 39.8 & 1709 & 25.3 \\
\hline $35-39$ & 45 & 1.3 & 625 & 18.6 & 670 & 9.9 \\
\hline $40-44$ & 2 & 0.1 & 89 & 2.6 & 91 & 1.4 \\
\hline $45-49$ & 0 & 0 & 32 & 1.0 & 32 & 0.5 \\
\hline $50-54$ & 0 & 0 & 13 & 0.4 & 13 & 0.2 \\
\hline \multicolumn{7}{|l|}{ Religion } \\
\hline Christianity & 573 & 17.0 & 557 & 16.5 & 1130 & 16.8 \\
\hline Islam & 2697 & 80.1 & 2648 & 78.7 & 5345 & 79.3 \\
\hline Traditional & 64 & 1.9 & 85 & 2.5 & 149 & 2.2 \\
\hline Others & 34 & 1.0 & 78 & 2.3 & 112 & 1.7 \\
\hline \multicolumn{7}{|l|}{ Education } \\
\hline No formal Sch. & 777 & 23.0 & 922 & 27.4 & 1699 & 25.2 \\
\hline Quranic & 1155 & 34.3 & 742 & 2.2 & 1897 & 28.2 \\
\hline Primary & 622 & 18.5 & 570 & 16.9 & 1192 & 17.7 \\
\hline Secondary & 627 & 18.6 & 744 & 22.1 & 1371 & 20.3 \\
\hline 'A'level/OND & 164 & 4.0 & 261 & 7.8 & 425 & 6.4 \\
\hline HND/University & 23 & 0.7 & 128 & 3.8 & 151 & 2.2 \\
\hline \multicolumn{7}{|l|}{ Occupation } \\
\hline Civil servant & 177 & 5.3 & 403 & 12.0 & 580 & 8.8 \\
\hline Trading/Business & 557 & 16.5 & 1081 & 32.1 & 1638 & 24.3 \\
\hline Farming & 599 & 17.8 & 1798 & 53.3 & 2397 & 35.5 \\
\hline Fuelwood & 89 & 2.6 & - & - & 89 & 1.3 \\
\hline \multicolumn{7}{|l|}{ Harvesting } \\
\hline Housewife & 1924 & 57.1 & - & - & 1924 & 28.5 \\
\hline Others & 22 & 0.7 & 86 & 2.6 & 108 & 1.6 \\
\hline \multicolumn{7}{|l|}{$\begin{array}{l}\text { Monthly Income } \\
\text { (Naira) }\end{array}$} \\
\hline$<10,000$ & 1846 & 54.8 & 858 & 25.5 & 2704 & 40.2 \\
\hline $10,001-20,000$ & 559 & 16.6 & 1100 & 32.7 & 1659 & 24.6 \\
\hline $20,001-30,000$ & 416 & 12.4 & 800 & 23.8 & 1216 & 18.1 \\
\hline $30001-40,000$ & 391 & 11.6 & 505 & 15.0 & 896 & 13.3 \\
\hline $40,001-50,000$ & 83 & 2.5 & 55 & 1.6 & 138 & 2.0 \\
\hline$>50,000$ & 69 & 2.0 & 50 & 1.4 & 119 & 1.8 \\
\hline
\end{tabular}

Source: Hospital Record and data analysis 2019 
Table 2 presents some socio-demographic characteristics of the parents of the under-five children under study. The Table shows that the majority $(41.6 \%)$ of the mothers of the children in the study were within the age brackets of 20-24 years and 25-29 years (35.4\%) while the fathers were mostly $(63.6 \%)$ in the age groups of $25-34$ years. The breakdown shows that $23.8 \%$ were within age groups of $25-29$ while $39.8 \%$ were in age groups of $30-34$ years. The median age was 22 years for the mothers and 32 years for the fathers.

The majority $(78.7 \%)$ of the parents were Muslims and about $25 \%$ of them did not have any form of formal education. Twenty-eight percent had Qur'anic education, comprising $34.3 \%$ of the women as against $2.2 \%$ of the men. Only $46.6 \%$ of them had some formal Western education (17.7\% Primary, 20.3\% Secondary and 8.6\% Tertiary).

The occupation of parents of the children is also presented in table 2. The table shows that about $35.5 \%$ of the parents of the children are farmers, 24.3 are into petty trading while $28.5 \%$ are housewives. The monthly income of the parents reveals that most $(40.2 \%)$ earned below ten-thousand-naira monthly and only $1.8 \%$ of the parents earned above fifty thousand naira monthly.

\section{Prevalent Childhood Diseases in the Study Area}

Of the 3,368 cases the under-fives sampled at the General Hospital Deba during the study period, malaria accounted for $2022(60.1 \%)$ of all the cases. This was followed by Diarrhoea diseases and Yellow fever, accounting for $11.5 \%$ and $11.0 \%$ of the cases respectively. Other less common presentations included pneumonia (4.1\%), malnutrition (3.2\%) and various skin diseases, principally scabies and boils (2.6\%). Details are presented in Table 3:

Table 3: Distribution of Prevalent Childhood Diseases among in the Study Area

\begin{tabular}{lll}
\hline Disease Type & Frequency & Percent \\
\hline $\begin{array}{l}\text { Pre-term } \\
\text { Complications }\end{array}$ & 52 & 1.5 \\
Malaria & 2022 & \\
Yellow Fever & 371 & 60.1 \\
Pneumonia & 138 & 11.0 \\
Diarrhoea & 386 & 4.1 \\
Malnutrition & 109 & 11.5 \\
Typhoid fever & 92 & 3.2 \\
Measles & 28 & 2.7 \\
Neonatal sepsis & 9 & 0.8 \\
Congenital & 6 & 0.3 \\
abnormality & & 0.2 \\
Tetanus & 51 & \\
Scabies/boils & 88 & 1.5 \\
Other types of fever & 16 & 2.6 \\
Total & 3368 & 0.5 \\
& & 100
\end{tabular}

Source: Hospital Record and data analysis 2019 


\section{Distribution of the major prevalent Diseases in the Study Area.}

The distribution of the major prevalent childhood diseases in the study area as obtained from the hospital records is shown in Figure 2.

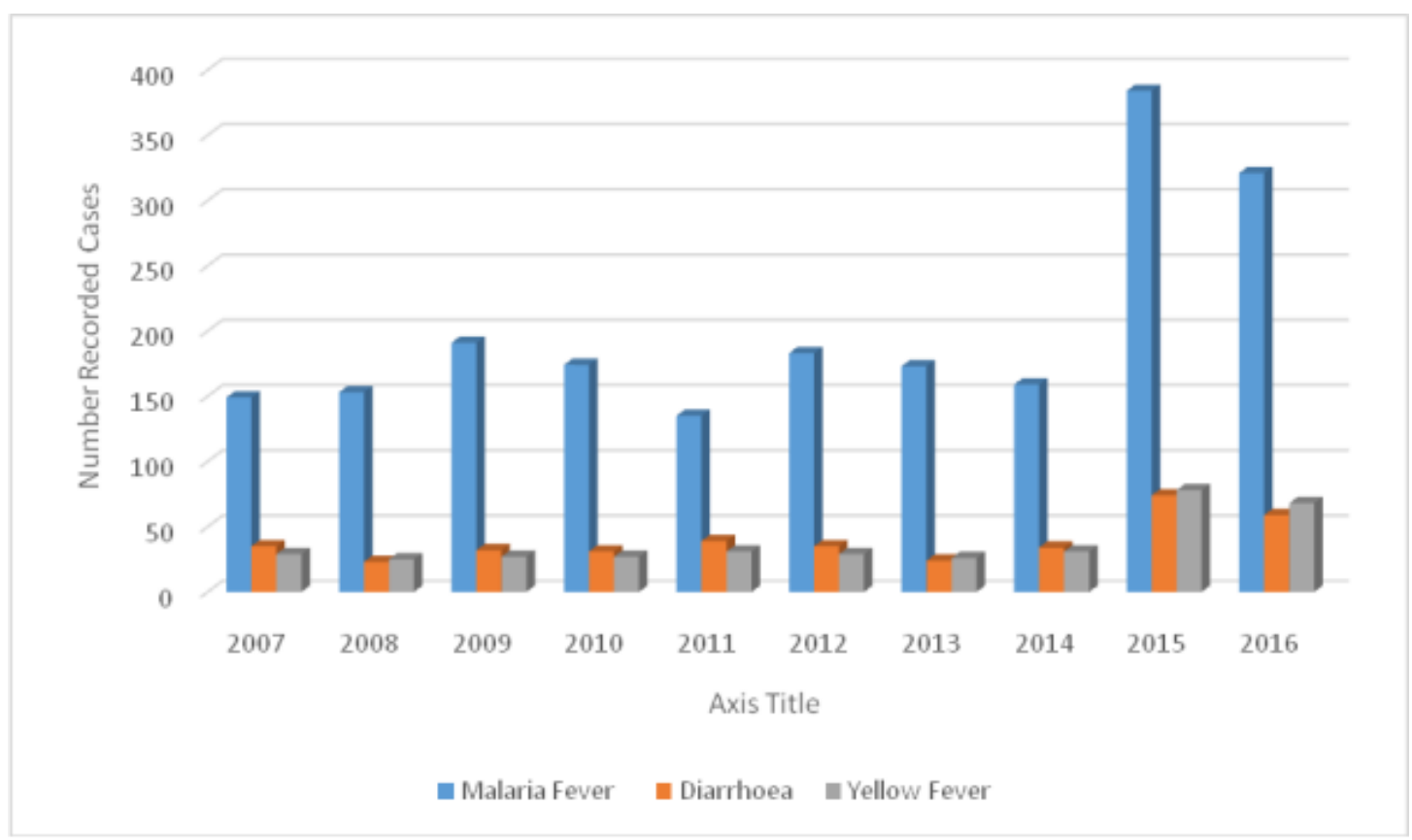

Fig 3: Prevalence of Malaria, Diarrhoea and Yellow Fever (2007-2016).

Figure 3 is a comparison of the three major childhood diseases in the study area. The figure reveals that throughout the 10 -year period under study, malaria was the dominant disease in the area even though its prevalence fluctuated between the years with a sharp increase in prevalence in 2015 and 2016. The other two diseases, Diarrhoea and yellow fever remained steady throughout the period with a slight increase in the last two years.

\section{Distribution of mortality by disease type}

The distribution of the mortality by disease type is shown in Figures 6 and 7. Figure 6 shows mortality due to all the childhood diseases in the study area with the highest mortality recorded in 2009. The figure indicates that under-five mortality rose from $18.2 \%$ in 2007 and reached its peak in 2009. Thereafter, it declined to $13.3 \%$ in 2013 and rose again to $18.8 \%$ in 2014 . However, a reason for fluctuation was not established. 


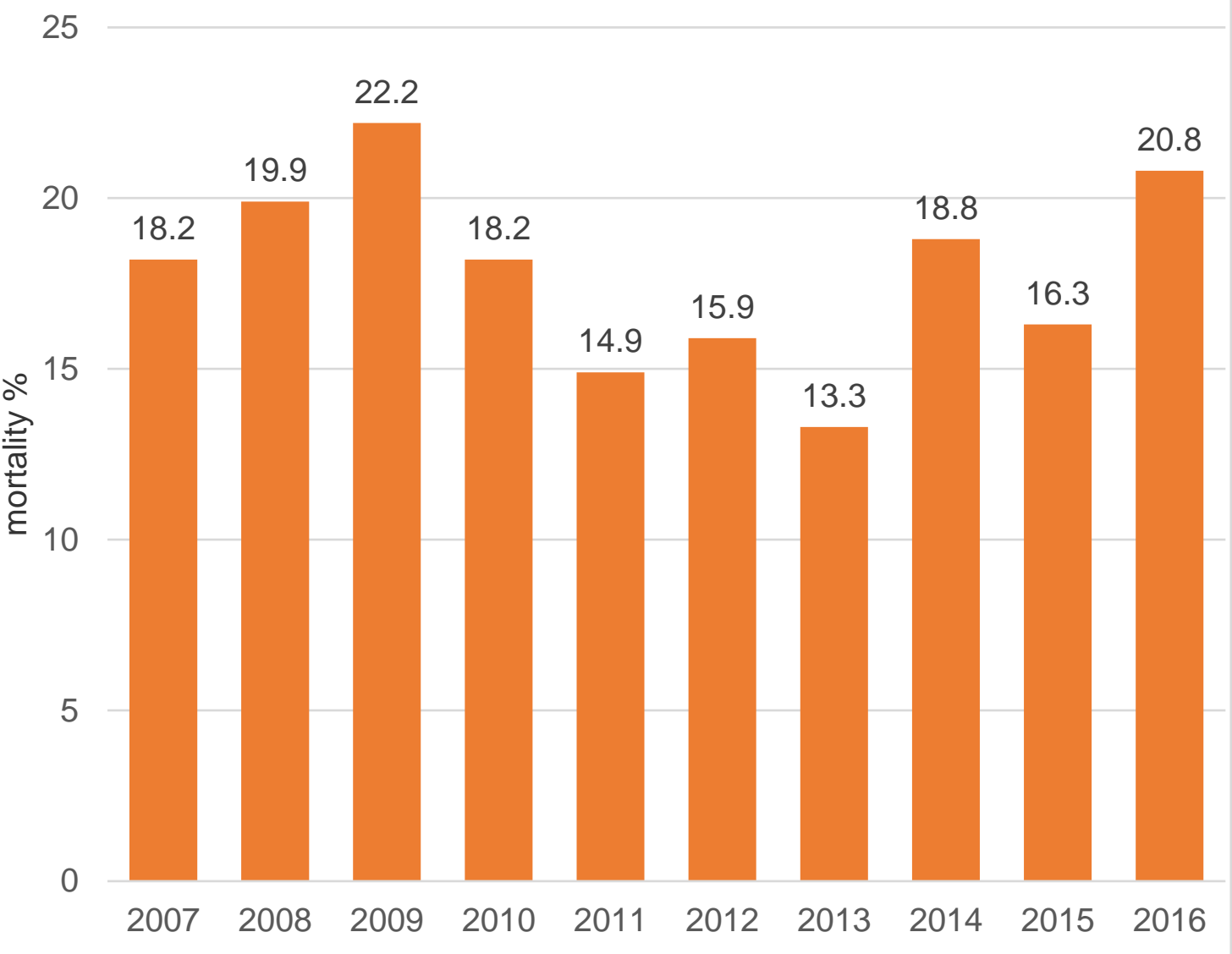

Figure 4: Distribution of Mortality by year from 2007-2016

Figure 5 shows the mortality rate by disease type for the ten-year period under study. The figure reveals that the highest mortality in the study area was due to malaria, accounting for $51.7 \%$ of the total mortality. This was followed by yellow fever which accounted for $17.4 \%$ of the total mortality in the study area. 


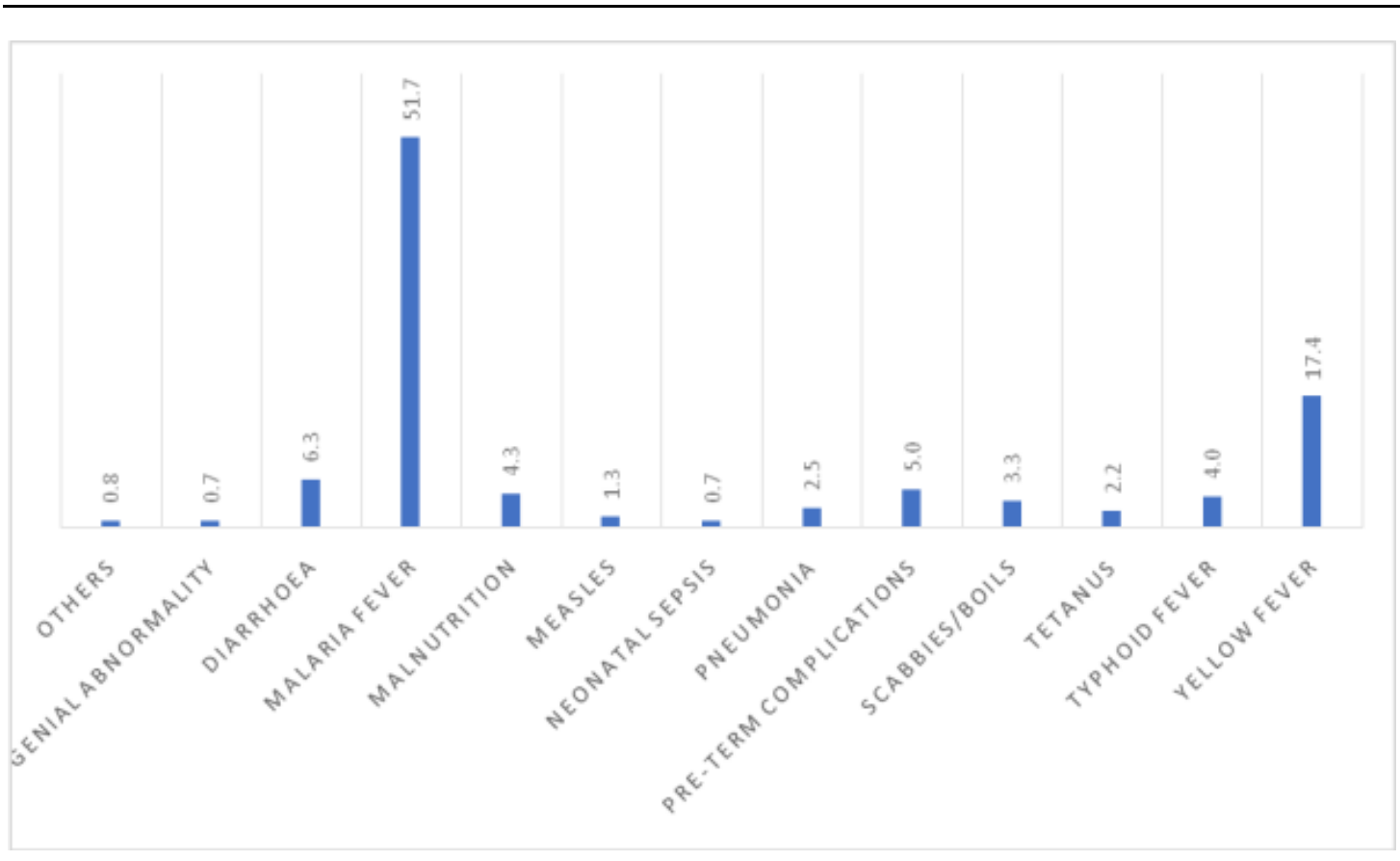

Fig 5: Deaths by Disease Type

Correlational Analysis of the Socio-Economic Variables

\section{Pearson's Correlation Coefficients}

\begin{tabular}{ccccccc}
\hline & Disease & Mortality & Religion & Education & Occupation & Income \\
Disease & 1 & & & & & \\
Mortality & 0.410 & 1 & & & & \\
Religion & $.601^{* *}$ & $.109^{* *}$ & 1 & & & \\
Education & $.553^{* *}$ & 0.501 & $.083^{* *}$ & 1 & & \\
Occupation & $.451^{* *}$ & 0.318 & $.111^{* *}$ & $.544^{* *}$ & 1 & \\
Income & $.366^{*}$ & $.742^{* *}$ & 0.026 & $.501^{* *}$ & $.950^{* *}$ & 1 \\
\hline
\end{tabular}

Source: SPSS output version 23.0

**. Correlation is significant at the 0.01 level (2-tailed).

*. Correlation is significant at the 0.05 level (2-tailed).

Income vs Disease: The correlation coefficient for Income and Disease is 0.366 which is a fairly weak linear relationship. Thus, the statistical hypothesis test for this p-value is: $\mathrm{H}_{0}$ : There is no significant relationship between Income and Disease. Since its $p<.05$, it shows that the relationship observed is statistically significant.

Income vs Mortality: The correlation coefficient for Income and Mortality is 0.742 which is a strong linear relationship. Thus, the statistical hypothesis test for this $\mathrm{p}$-value is: $\mathrm{H}_{0}$ : There is no significant relationship between Income and Mortality. Since its $p<.05$, the null of no relationship is then rejected and, therefore, we conclude that the relationship observed is statistically significant. 
Religion vs Disease: The correlation coefficient for Religion and Disease is 0.601 which is a strong linear relationship. Thus, the statistical hypothesis test for this p-value is: Ho: There is no significant relationship between Religion and Disease. Versus $\mathrm{H}_{\mathrm{a}}$ : There is a statistically significant relationship between Religion and Disease. Since its $p<.05$, the null of no relationship is then rejected and, therefore, we conclude that the relationship observed is statistically significant.

Religion vs Mortality: The correlation coefficient for Religion and Mortality is 0.109 which is a very weak linear relationship. Thus, the statistical hypothesis test for this p-value is: $\mathrm{H}_{0}$ : There is no significant relationship between Religion and Mortality. Versus $\mathrm{H}_{\mathrm{a}}$ : There is a statistically significant relationship between Religion and Mortality. Since its $p<.05$, the null of no relationship is then rejected and, therefore, we conclude that the relationship observed is statistically significant.

Education vs Disease: The correlation coefficient for Education and Disease is 0.553 which is a moderately strong linear relationship. Thus, the statistical hypothesis test for this p-value is: $\mathrm{H}_{0}$ : There is no significant relationship between Education and Disease. Versus $\mathrm{H}_{\mathrm{a}}$ : There is a statistically significant relationship between Education and Disease. Since its $p<.05$, the null of no relationship is then rejected and therefore we conclude that the relationship observed is statistically significant.

Education vs Mortality: The correlation coefficient for Education and Mortality is 0.501 which is a moderately strong linear relationship. Thus, the statistical hypothesis test for this pvalue is: $\mathrm{H}_{0}$ : There is no significant relationship between Education and Mortality. Versus $\mathrm{H}_{\mathrm{a}}$ : There is a statistically significant relationship between Education and Mortality. Since its $\mathrm{p}<$ .05 , the null of no relationship is then rejected and therefore we conclude that the relationship observed is statistically significant.

Occupation vs Disease: The correlation coefficient for Occupation and Disease is 0.451 which is a fairly weak linear relationship. Thus, the statistical hypothesis test for this p-value is: $\mathrm{H}_{0}$ : There is no significant relationship between Occupation and Disease. Versus $\mathrm{H}_{\mathrm{a}}$ : There is a statistically significant relationship between Occupation and Disease. Since its $p<.05$, the null of no relationship is then rejected and therefore we conclude that the relationship observed is statistically significant.

Occupation vs Mortality: The correlation coefficient for Occupation and Mortality is 0.318 which is a weak linear relationship. Thus, the statistical hypothesis test for this p-value is: $\mathrm{H}_{0}$ : There is no significant relationship between Occupation and Mortality. Versus $\mathrm{Ha}_{\mathrm{a}}$ There is a statistically significant relationship between Occupation and Mortality. Since its $p>.05$, the null of no relationship cannot be rejected and therefore we conclude that the relationship observed is not statistically significant. 


\section{REGRESSION ANALYSIS}

\section{MODEL 1: DISEASE}

\section{Model Summary}

\begin{tabular}{|l|l|r|r|r|}
\hline Model & R & R Square & Adjusted R Square & Std. Error of the Estimate \\
\hline 1 & $.860^{\mathrm{a}}$ & .700 & .612 & 3.54889 \\
\hline
\end{tabular}

a. Predictors: (Constant), Income, Religion, Occupation, Education

Source: SPSS output version 23.0

The model summary table above provides the $R$ and $R^{2}$ values. The $R$-value represents the simple correlation and is 0.860 (the "R" Column), which indicates a high degree of correlation among the variables in the model. The $R^{2}$ value (the "R Square" column) indicates how much of the total variation in the dependent variable (Disease) can be jointly explained or accounted for by the independent variables (Income, Religion, Occupation, Education). In this case, 70\% of the diseases caused can be explained or accounted for by the independent variables (Predictors), which is very large, leaving only $30 \%$ variability unexplained or caused by some other extraneous variables.

\section{ANOVA ${ }^{\mathrm{a}}$}

\begin{tabular}{|ll|r|r|r|r|r|}
\hline \multicolumn{2}{|l|}{ Model } & \multicolumn{1}{|c|}{ Sum of Squares } & Df & Mean Square & F & \multicolumn{1}{c|}{ Sig. } \\
\hline 1 & Regression & 312.105 & 4 & 78.026 & 6.195 & $.000^{\mathrm{b}}$ \\
& Residual & 42280.107 & 3357 & 12.595 & & \\
& Total & 42592.212 & 3361 & & & \\
\hline
\end{tabular}

a. Dependent Variable: Disease

b. Predictors: (Constant), Income, Religion, Occupation, Education

Source: SPSS output version 23.0

As seen from the regression analysis of variance table above. It was observed that the regression model predicts the dependent variable significantly well. Since the "Sig." column returns a pvalue of 0.000 (i.e., $p<0.0005$ ), which is less than 0.05 , and thus indicates that, overall, the regression model statistically significantly predicts the "disease" variable. Hence the model is well fit for the data.

\section{Coefficients ${ }^{\mathrm{a}}$}

\begin{tabular}{|c|c|c|c|c|c|c|}
\hline \multirow{2}{*}{\multicolumn{2}{|c|}{ Model }} & \multicolumn{2}{|c|}{$\begin{array}{c}\text { Unstandardized } \\
\text { Coefficients }\end{array}$} & \multirow{2}{*}{$\begin{array}{c}\text { Standardized } \\
\text { Coefficients } \\
\text { Beta }\end{array}$} & \multirow[b]{2}{*}{$\mathrm{T}$} & \multirow[b]{2}{*}{ Sig. } \\
\hline & & $\mathrm{B}$ & Std. Error & & & \\
\hline \multirow[t]{5}{*}{1} & (Constant) & 4.598 & .314 & & 14.657 & .000 \\
\hline & Religion & .862 & .092 & .544 & 3.102 & .002 \\
\hline & Education & .760 & .037 & .383 & 2.058 & .040 \\
\hline & Occupation & .992 & .076 & .245 & 1.304 & .192 \\
\hline & Income & .451 & .030 & .265 & 1.492 & .136 \\
\hline
\end{tabular}

a. Dependent Variable: Disease

Source: SPSS output version 23.0 
The regression model is stated as follows:

$D I S E A S E=.862 R E L+.760 E D U+.9920 C C+.451 I N C+4.598 \ldots \ldots \ldots . .$. Equation 1

The regression analysis results in the Coefficients table above indicate that Religion and Education significantly predict "Disease" whereas Occupation and Income did not. The result further indicates that "Religion" which yielded a Beta $(\boldsymbol{\beta})$ value of .862, t-value of 3.102, and a p-value of .002, was significant since the p-value is less than 0.05 level of significance. This implies that a unit change in the level of "Religious activities" (a unit increase or decrease) will significantly have a corresponding effect on the "Disease" by a factor of 0.862 . Also, the variable "Education" which yielded a Beta $(\boldsymbol{\beta})$ value of .760, t-value of 2.058 , and a p-value of .040 , was significant since the $\mathrm{p}$-value is less than 0.05 level of significance.

However, the variable "Occupation" which yielded a Beta $(\boldsymbol{\beta})$ value of .992 , t-value of 1.304, and a p-value of .192, was not significant since the p-value is not less than 0.05 level of significance. This implies that a unit change in the level of occupational activities (a unit increase or decrease) will not significantly predict the Disease (score) of the respondents. Lastly, the variable "Income" which yielded a Beta $(\boldsymbol{\beta})$ value of .451, t-value of 1.492, and a $\mathrm{p}$-value of .136, was not significant since the p-value is not less than 0.05 level of significance.

\section{MODEL 2: MORTALITY}

\section{Model Summary}

\begin{tabular}{|l|r|r|r|r|}
\hline Model & R & R Square & $\begin{array}{c}\text { Adjusted R } \\
\text { Square }\end{array}$ & $\begin{array}{c}\text { Std. Error of } \\
\text { the Estimate }\end{array}$ \\
\hline 1 & $.536^{\mathrm{a}}$ & .418 & .417 & .38046 \\
\hline
\end{tabular}

a. Predictors: (Constant), Income, Religion, Occupation, Education

Source: SPSS output version 23.0

The model summary table above provides the $R$ and $R^{2}$ values. The $R$-value represents the simple correlation and is 0.536 (the "R" Column), which indicates a high degree of correlation among the variables in the model. The $R^{2}$ value (the "R Square" column) indicates how much of the total variation in the dependent variable (Mortality) can be jointly explained or accounted for by the independent variables (Income, Religion, Occupation, Education). In this case, $41.8 \%$ of the mortality causes can be explained or accounted for by the independent variables (Predictors), which is on average leaving only $58.2 \%$ variability unexplained or caused by some other extraneous variables. 


\begin{tabular}{|c|c|c|c|c|c|c|}
\hline \multicolumn{7}{|c|}{ ANOVA $^{a}$} \\
\hline & & $\begin{array}{c}\text { Sum of } \\
\text { Squares }\end{array}$ & $\mathrm{df}$ & Mean Square & $\mathrm{F}$ & Sig. \\
\hline 1 & Regression & 9.103 & 4 & 2.276 & 15.722 & $.000^{\mathrm{b}}$ \\
\hline & Residual & 486.514 & 3361 & .145 & & \\
\hline & Total & 495.617 & 3365 & & & \\
\hline
\end{tabular}

a. Dependent Variable: Mortality

b. Predictors: (Constant), Income, Religion, Occupation, Education

Source: SPSS output version 23.0

As seen from the regression analysis of variance table above. It was observed that the regression model predicts the dependent variable significantly well. Since the "Sig." column returns a pvalue of 0.000 (i.e., $p<0.0005$ ), which is less than 0.05 , and thus indicates that, overall, the regression model statistically significantly predicts the "Mortality" variable. Hence, the model is well fit for the data.

\section{Coefficients ${ }^{\mathrm{a}}$}

\begin{tabular}{|c|c|c|c|c|c|c|}
\hline \multirow{2}{*}{\multicolumn{2}{|c|}{ Model }} & \multicolumn{2}{|c|}{$\begin{array}{c}\text { Unstandardized } \\
\text { Coefficients }\end{array}$} & \multirow{2}{*}{$\begin{array}{c}\text { Standardized } \\
\text { Coefficients } \\
\text { Beta }\end{array}$} & \multirow[b]{2}{*}{$\mathrm{T}$} & \multirow[b]{2}{*}{ Sig. } \\
\hline & & B & Std. Error & & & \\
\hline \multirow[t]{5}{*}{1} & (Constant) & 1.042 & .034 & & 30.997 & .000 \\
\hline & Religion & .651 & .010 & .413 & 6.560 & .000 \\
\hline & Education & .102 & .004 & .110 & .582 & .561 \\
\hline & Occupation & .120 & .008 & .272 & 1.494 & .135 \\
\hline & Income & .143 & .003 & .764 & 4.378 & .000 \\
\hline
\end{tabular}

ssa. Dependent Variable: Mortality

Source: SPSS output version 23.0

The regression model is stated as follows:

$D I S E A S E=0.651 R E L+0.102 E D U+0.1200 C C+0.651 I N C+1.042 \ldots \ldots$ Equation 2

The regression analysis results in the Coefficients table above indicate that Religion and Income significantly predict "Mortality" whereas Occupation and Education did not. The result further indicates that "Religion" which yielded a Beta $(\boldsymbol{\beta})$ value of .651, t-value of 6.560, and a p-value of .000 , was significant since the p-value is less than 0.05 level of significance. This implies that a unit change in the level of "Religious activities" (a unit increase or decrease) will significantly have a corresponding effect on the "Mortality" by a factor of 0.651 . Also, the variable "Education" which yielded a Beta $(\boldsymbol{\beta})$ value of 0.102 , t-value of 0.528 , and a p-value of 0.561 , was not significant since the $\mathrm{p}$-value is not less than 0.05 level of significance.

However, the variable "Occupation" which yielded a Beta $(\boldsymbol{\beta})$ value of 0.120 , t-value of 1.494, and a p-value of 0.135 , was not significant since the p-value is not less than 0.05 level of significance. Lastly, the variable "Income" which yielded a Beta $(\boldsymbol{\beta})$ value of 0.143 , t-value of 4.378 , and a p-value of 0.000 , was significant since the p-value is less than 0.05 level of significance. 


\section{DISCUSSION}

The study showed that malaria was the commonest disease among the under-fives in the study area, accounting for $60.1 \%$ of all the illnesses recorded at the Deba General Hospital over the 10 -year study period. This was similar to the $58.2 \%$ prevalence of malaria in Awka North Local Government Area of Anambra State, South Eastern Nigeria reported by Nwaorgu and Rajaku(2011). The prevalence is higher than the 32.3\% reported by Jombo et al(2010) in Makurdi, North Central Nigeria, ${ }^{8}$ the $35.7 \%$ reported by Umaru and Uyaiabasi(2015) in Makarfi, North-Western Nigeria and $50.6 \%$ reported by Kunihya et al(2016) in Yola, Adamawa, North-Eastern Nigeria. However, Ezeigbo et al (2014) reported a higher prevalence rate of $65.0 \%$ in Aba, South Eastern Nigeria and Obanyo et al (2007) reported $82.5 \%$ in Western Kenya.

The equally high prevalence of diarrhoeal disease corroborates the earlier report by Boschi et al,(2008) who posited that diarrhoeal disease is among the leading causes of morbidity and mortality in under-five children in developing countries. Similarly, Adamu et al (2014) in Jekadafari, Gombe Metropolis reported that malaria, cholera and diarrhoea were the three leading causes of mortality among under-five children. The WHO (2006) estimated that 2.5 billion cases of diarrhoeal occur among under-five children globally and more than half of the cases occurred in Africa and Asia. The report indicated that diarrhoeal disease was the fourth leading cause of mortality among under-five in Nigeria.

The study further established the increase in the prevalence of diseases in the last two years under the period of study. The last two years coincided with the period the present administration took over power in Nigeria but that is not to say this is responsible for the increased prevalence of diseases in the study area within the period. However, the perception of the participants in most of the focus group discussions held across the rural communities could be deduced as a likely reason. The popular opinion is that:

\section{"Awannanmulki, rayuwa ta yi mana wuya. Ba kudiabinci dana biyanmakarantanyara da nazuwaasibiti.Yazamana dole mu nemawarkaswaawujemasumaganingargaja.' (Translated as- in this regime, things are extremely difficult for us. There is no money for food, no money to pay our wards school fees or even to seek medication in the hospital. It becomes necessary for us to seek treatment from the traditional healers (herbalists)."}

The study established that the majority (54.5\%) of the respondents have a family size of 5 and above. This large family size has health implications on the children as there will be competing needs for the meagre resources of the family especially in the area of food provision, health among others as the children are not well fed, there is the possibility that they will become susceptible/vulnerable to diseases.

This study also found that as many as $53.4 \%$ of the parents had either Qur'anic education or no formal education at all, and only $46.6 \%$ had some formal Western education. The significance of education of parents especially that of mothers on the health status of the children has been established by Oloruntoba et al,(2014) in a study of under-five diarrheal disease in Ibadan, South-Western Nigeria among others. 
Information on the income of parents shows that the majority (40.2\%) earned below tenthousand-naira monthly while $24.6 \%$ earned between $10,000-20,000$ naira per month with most engaging in farming (35.5\%) and trading/business (24. 3\%). This shows that there is a high level of poverty in the study area. This has great implications on the health of the population as the income level influences the affordability and quality of food, as well as the health-seeking behaviours of the people. Similarly, the low-income level in the study has an effect on the availability and quality of houses in the area as more than 4 people sleep in a room in about $78 \%$ of households. This no doubt has an effect on the health of the occupants as the room is overcrowded making it easy for the spread of contagious disease-where a member is infected.

About $61 \%$ of the deaths reported in the study area were those taken to a traditional healer, while $28 \%$ occurred at home. Only $24 \%$ of the mortalities were at health care centres. This is possibly due to the belief held by the people about some diseases which they believed cannot be treated in hospitals. It may not be unlikely due to inadequate finances to seek treatment for the child in the hospital due to the high cost of treatment through this means.

The study also shows that out of the 531 healthcare facilities located in Gombe state as of 2014, only $12 \%(62)$ are located in the study area. About 59 of the healthcare facilities are Primary Health care (PHC) while only 3 are secondary health care facilities. This shows that there is no efficient distribution of health facilities in the study area. This implies that the populations have to cover a long distance to access the health facilities which have some implications on their wellbeing.

The correlation coefficient of 0.366 for Income and Disease shows a fairly weak but significant relationship. Similarly, the correlation coefficient of 0.601 for Religion and Disease indicates a strong and significant linear relationship. Furthermore, the correlation coefficient for Education and Disease is 0.553 which shows a moderate but strong significant linear relationship. More so, the correlation coefficient for Occupation and Disease is 0.451 which is a fairly weak linear but significant relationship. The regression analysis with an R-value of 0.860 indicates a very high degree of correlation among the variables. While the $R^{2}$ value indicates how much of the total variation in the dependent variable (Disease) can be jointly explained or accounted for by the independent variables (Income, Religion, Occupation, and Education). In this case, $70 \%$ of the diseases caused can be explained or accounted for by income, religious occupation and education. The regression analysis Coefficients indicates that Religion and Education significantly predict "Disease". The result further indicates that "Religion" which yielded a Beta $(\boldsymbol{\beta})$ value of .862, t-value of 3.102, and a p-value of .002, was significant. This implies that a unit change in the level of "Religious activities" (a unit increase or decrease) will significantly have a corresponding effect on the "Disease" by a factor of 0.862. Also, the variable "Education" which yielded a Beta $(\boldsymbol{\beta})$ value of .760, t-value of 2.058 , and a p-value of .040, was significant which also implies that a unit change in the level of "Education" (a unit increase or decrease) will significantly affect the "Disease by a factor of .760 .

Similarly, the correlation coefficient for Income and Mortality is 0.742 which shows a strong significant linear relationship. The correlation between religion and mortality with a value of 0.109 indicates a very weak but significant relationship. Furthermore, the correlation coefficient for Education and Mortality is 0.501 which is a moderately strong and significant linear relationship. The correlation coefficient for Occupation and Mortality which is 0.318 
also shows a weak but significant linear relationship. The regression analysis with an R-value of 0.536 indicates a high degree of correlation among the variables in the model. This indicates how much of the total variation in the dependent variable (Mortality) can be jointly explained or accounted for by the independent variables (Income, Religion, Occupation, Education). In this case, $41.8 \%$ of the mortality causes can be explained or accounted for by the independent variables (Predictors), which is on average leaving only 58.2\% variability unexplained or caused by some other extraneous variables. The regression analysis Coefficients indicates that Religion and Income significantly predict "Mortality". The result further indicates that "Religion" which yielded a Beta $(\boldsymbol{\beta})$ value of .651, t-value of 6.560, and a p-value of .000, was significant since the $\mathrm{p}$-value is less than 0.05 level of significance. This implies that a unit change in the level of "Religious activities" (a unit increase or decrease) will significantly have a corresponding effect on the "Mortality" by a factor of 0.651 . While "Income" which yielded a Beta $(\boldsymbol{\beta})$ value of 0.143 , t-value of 4.378 , and a $p$-value of 0.000 , was significant since the $p$ value is less than 0.05 level of significance. This implies that a unit change in the level of the respondent's income (a unit increase or decrease) will significantly predict the mortality rate of the respondents by a factor of 0.143 .

\section{CONCLUSION}

The study concludes that malaria, diarrheal diseases and yellow fever are the major childhood diseases in the Yamaltu/Deba Local Government Area of Gombe State. It was observed that the incidence of these diseases increased in the last two years under investigation (2015-2016). Furthermore, malaria and yellow fever are the major killers of children in the study area. Low income, low level of education, high room density, poor health-seeking behaviours, cultural and religious beliefs, is among factors influencing child mortality and morbidity in the study area.

Programmes and policies aimed at addressing the health needs of the population should be enhanced. Poverty eradication/alleviation programmes should be instituted for the people in the area. There is also a need to create awareness on health education of mothers and the general education of the rural population of the study area. This will go a long way in reducing the prevalence of diseases and mortality in the study area.

\section{Acknowledgements}

The support from the Tertiary Education Trust Fund (TETFund) and the University of Abuja, in the form of research grants are acknowledged with thanks. Rauf Ibrahim of the Department of Statistics, University of Abuja was very helpful with the analysis of the data. 


\section{REFERENCES}

[1]. Child Care: 5 most common Diseases Affecting Children under 5 years. http://www.nigerianbullentin.com.Posted Jul 2, 2015: Accessed 23 March 2018.

[2]. World Health Organization(2005). World malaria report 2005. WHO: Regional Office for Africa, Geneva. http://www.afro.who.int/index.php?optio.=com_docman\&g.d=479_Accessed 18 May 2018.

[3]. http://www.prb.org/pdf14/2014-worldpopulationdata-heet_eng.pdf. Accessed 18 September 2017

[4]. National Population Commission (NPC) \& ICF International. Nigeria Demographic Health Survey (NDHS): 2013 Final Report.

[5]. Gayawan E, Arogundade E.D, Adebayo S.R (2014). Possible determinants and spatial patterns of anaemia among young children in Nigeria: Bayesian semi-parametric modelling. Int. Health 2014;6.35-45

[6]. Nwaorgu O.C and Orajaka B.N.(2011). Prevalence of Malaria among Children 1-10 Years old in Communities in Awka North Local Government Area, Anambra State South-East Nigeria. Inter. Mult. J., Ethop., 5(5): 2011. 264-281.

[7]. Ezeigbo O.R, Osuagwu M.C, Ezike M.N, Ibegbulem Z.O, Kalu S.(2014). Malaria Parasitaemia in Children Aged 1-5 Years in Aba, South Eastern Nigeria. US Open Genl. Microbiol. J. 1(1):2014. 1-6.

[8]. Jombo G.T.A, Mbaawuaga E.M, Anongu S.T, Egah D.Z, Enenebeaku M.N.O, Peters E.J, Utsalo S.J, Okwori E.E, Odey F.(2010). The Burden of Malaria among under 5 Children: Finding from Makurdi City, North Central Nigeria. Rev. Infect., 1(3):2010. 140-144.

[9]. Umaru M.L, Uyaiabasi G.N.(2015). Prevalence of malaria in patients attending the General Hospital Makarfi, Makarfi Kaduna- State, North-Western Nigeria. Am. J. Infect. Dis. Microbiol., 3(1):2015. 1-5.

[10]. Kunihya, I. Z., Samaila, A. B., Nassai, I., Sarki, A. Haruna, M. Y.(2016). Prevalence of Malaria Infection among Children Attending Specialist Hospital Yola, Adamawa State, Nigeria. Journal of Medical and Biological Science Research Vol.2(8), August2016.136142. http://pearlresearchjournals.org/journals/jmbsr/index.html

[11]. Feyisetan BJ, Asa S, Ebigbola JA.(1997). Mothers' management of childhood iseases in Yorubaland: The influence of cultural beliefs. Health Transit. Rev., 7:1997. 221-234.

[12]. Obonyo CO, VululeJ, Akhwale WS, GrobberDE (2007). In-Hospital morbidity and mortality due to severe malaria anaemia in Western Kenya. Am. J. Trop. Med Hyg., 77(6):2007. 23-8.

[13]. Boschi-Pinto C, Velebit L, Shibuya K.(2008). Estimating child mortality due to diarrhoea in developing countries. Bulletin of WHO. 2008;86(9):710-717.

[14]. Adamu, S.J, Ibrahim, A.Q and Mahmoud, A.B.(2014). An Assessment of ChildKiller Disease in Relation to Environment: Case Study of Jekadafari Gombe-

Nigeria. Journal of Medical and Applied Biosciences Volume 6, Number 1. 2014

[15]. World Health Organization(2006). Reducing mortality from major childhood Kille diseases. Mortality Country Fact Sheet.2006. https://apps.who.int/chd/publications/imci/fs_180.htm.

[16]. Oloruntoba, E.O, Falarin T.B, Ayede A.I.(2014). Hygiene and Sanitation risk factors of diarrhoeal disease among under-five children in Ibadan, Nigeria. Afri. Health Sci; 014 Dec: 14(4). 2014. 1001-1011 